\title{
There is more to perinatal mental health care than depression: Public health nurses reported engagement and...
}

Article in Journal of Clinical Nursing · August 2017

DOI: $10.1111 /$ jocn.13986

CITATIONS

0

5 authors, including:

Agnes Higgins

Trinity College Dublin

129 PUBLICATIONS 1,076 CITATIONS

SEE PROFILE
READS

338

\section{Carmel Downes}

Trinity College Dublin

16 PUBLICATIONS 58 CITATIONS

SEE PROFILE

Some of the authors of this publication are also working on these related projects:

This project was funded by the Mental Health Commission after a competitive funding call for

Project Research Programme Grants in Mental Health Services Research into research related to Part 2 of the Mental Health Act 2001 (Lead Applicant: Prof. Colm McDonald). View project

Perspectives of Partners of Mothers who experience Mental Distress in the Postnatal Period (PMD 
Please Cite as Higgins A; Downes C; Carroll M; Gill A; Monahan M (2017) There is more to perinatal mental health care than depression: public health nurses' reported engagement and competence in perinatal mental health care Journal of Clinical Nursing

DOI: $10.1111 /$ jocn. 13986

\title{
There is more to perinatal mental health care than depression: public
} health nurses' reported engagement and competence in perinatal mental

\section{health care}

\begin{abstract}
Aim: To explore public health nurses' engagement, competence and education needs in relation to perinatal mental health care in Ireland.
\end{abstract}

Background: It is estimated that $15-25 \%$ of women will experience a mental health problem during or post pregnancy, either as a new problem or a reoccurrence of a pre-existing problem. Public Health Nurses, or their equivalent, are ideally positioned to support women's mental health and improve health outcomes for the woman and baby, yet little is known about their role and engagement with mental health issues, other than with postnatal depression. The objectives of the study were to identify public health nurses' knowledge, skills and current practices in perinatal mental health and establish their education needs.

Design: The research used a descriptive design.

Method: 186 public health nurses completed an anonymous, online-survey, designed by the research team.

Results: While public health nurses are positive about their role in supporting women's mental health, they lack the knowledge and skills to address all aspects of mental health, including opening a discussion with women on more sensitive or complex issues, such as 
trauma and psychosis and providing information to women. Those who received education reported statistically significant higher knowledge and confidence scores than those without. Conclusion: Public health nurses lack the knowledge and skills required to provide comprehensive perinatal mental health care to women. Future education programmes needs to move beyond postnatal depression and address the range of mental health problems that may impact on women in the perinatal period.

Relevance to clinical practice: Without knowledge and skill among nurses in all aspects of perinatal mental health women with significant mental health needs may be left to cope alone and lack the necessary prompt evidence-based interventions and supports.

Key words: perinatal mental health, public health nurses, knowledge and skills, education

\section{Summary statement}

\section{What does this paper contribute to the wider global clinical community?}

Internationally, the research available on nurses working in the community and tasked with providing perinatal mental health care is focused on postnatal depression. This paper takes a more comprehensive approach to defining perinatal mental health and includes issues that frequently go unrecognised such as bipolar disorder, psychosis, anxiety, obsessive thinking or behaviour, self-harm and eating disorders.

The findings are highly relevant as they identify the need for nurses to adopt a more comprehensive approach towards screening and assessment of risk factors and to develop the knowledge and skills to address all aspects of perinatal mental health, including the more sensitive or complex issues, such as trauma and psychosis. 


\section{INTRODUCTION}

For most women, pregnancy and motherhood is a positive psychological process; however, for some women this life-changing event can result in a mental health problem. It is estimated that $15-25 \%$ of women will experience a mental health problem either during pregnancy or in the first year post pregnancy (NICE, 2014), either as a new problem or as a reoccurrence of a pre-existing mental health problem. Despite the prevalence of perinatal mental health problems (PMHPs), they frequently go unrecognised by health care practitioners. Providing psychological support to mothers, children and families in the perinatal period is considered an important global health issue (Beyondblue, 2008; WHO, 2013), as early detection of distress, prompt intervention, and support can improve maternal and infant outcomes. The role of the nurse who works in the community and is tasked with providing a proactive service to support and care for women, babies and families during the perinatal period is increasing in importance given that hospital stay post birth is declining in all western countries. Similar to international figures, in the Republic of Ireland (ROI), the average length of stay for singleton birth is 2.5 days, with over $90 \%$ of singleton mothers who undergo caesarean birth being discharged from hospital three to five days after childbirth (HSE, 2016: 55-56). For women who experience perinatal mental health issues, this nurse role takes on greater significance, as they are the nurses that most often meet with women and their families in the postpartum period and are identified as a key support person for women within the international literature (Chew-graham et al. 2008; Glavin et al. 2010a; Rollans et al. 2013; Tammentie et al. 2013; Agapidaki et al. 2014; Noonan et al. 2017).

Known as Health Visitors or Specialist Community Public Health Nurses in the UK (Rollans et al. 2013), Child and Family Health Nurses (CFHNs) in Australia, Plunket Nurses in New Zealand, they are termed Public Health Nurses (PHNs) in Canada, Sweden, Holland and Ireland. Within Ireland, the PHN service comprises the largest group of nurses employed in 
the Irish community setting. PHNs provide a range of interventions that span the lifespan, including maternal and child health services within geographically defined caseloads. Despite this, studies into the role of the PHN in Ireland in the context of perinatal mental health $(\mathrm{PMH})$ are sparse, with studies in other countries primarily focusing on postnatal depression (Almond and Lathlean, 2011; Rush, 2012; Rollans et al. 2013; Borglin et al. 2015).

This paper takes a more comprehensive approach towards defining perinatal mental health problems and reports the findings of a study that explored PHNs' reported engagement, competence and needs in relation to issues.

\section{Perinatal Mental Health Problems}

It is estimated that between $7-15 \%$ of women will experience antenatal and postnatal depression (NICE, 2014), with women with a prior history of depression or antenatal depression being at an increased risk of depression in the postnatal period (Glasser et al. 2016). Similar to antenatal depression, perinatal anxiety is frequently underdiagnosed or misdiagnosed, yet it is a significant mental health issue (Vesga-Lopez et al. 2008). The rate of anxiety disorders is estimated to be between 14-15\% (SIGN, 2012; NICE, 2014), while approximately two-thirds of women who experience perinatal depression have co-morbid anxiety (Wisner et al. 2013). Pregnancy and early mothering can also increase vulnerability to obsessive thinking and, while intrusive thoughts are common in the perinatal period, they may cause significant distress to women. The content of obsessive, intrusive thoughts is often influenced by the woman's context (Barber, 2009), and therefore may be focused on the foetus, the birth, the woman herself or her partner. Obsessive and intrusive thoughts or images of harming the baby are not uncommon. In addition, the perinatal period may be a time of increased risk of developing obsessive compulsive disorder (OCD), with the prevalence rates for postnatal OCD ranging between 4-9\% (Challacombe and Wroe 2013). 
Postpartum psychosis, which is considered the most severe mental health problem in the puerperium, is estimated to affect one or two women per 1,000 births across all cultures (NICE, 2007). However, women with a prior history of bipolar disorder, especially those who stop medication abruptly, have a reported reoccurrence rate approaching $50 \%$ in the antenatal period and 70\% in the postnatal period (Viguera et al. 2007; Wesseloo et al. 2016). Similarly, women with a diagnosis of schizophrenia, other types of psychosis or those that have experienced a previous postpartum psychosis are also at increased risk (Munk-Olsen et al. 2009).

Research also suggests that there are higher rates of Post-Traumatic Stress Disorder (PTSD) in perinatal women, particularly in those that have already been affected by childhood abuse or traumatic experiences, including childbirth (Hinton et al. 2015). Studies have also highlighted the potential for reoccurrence and/or the worsening of a pre-existing binge eating disorder (Watson et al. 2013). Evidence also suggests that substance misuse during pregnancy has increased over the last three decades (Desai et al. 2014; Passey et al. 2014). The potential for intimate partner violence (IPV) to begin or escalate is understood to significantly increase during pregnancy (Jeanjot et al. 2008; Taillieu and Brownridge, 2010). Hence, the importance of nurses taking a comprehensive approach towards mental health throughout pregnancy, birth and early motherhood.

\section{Public Health Nursing's role in perinatal mental health care}

While little is known about how public health nurses working in Ireland enact their role in relation to women's perinatal mental health, studies elsewhere indicate that PHNs perceive that they have a role in the early identification, education, support and referral of women experiencing mental health problems (Rollans et al. 2013; Borglin et al. 2015). In some 
studies PHNs identified their role as giving positive feedback, affirmation and support to new mothers (Rush, 2012; Tammentie et al. 2013; Rollans et al. 2013; Borglin et al. 2015), as well as acting as a positive role model in how to interact with the baby (Tammentie et al. 2013). Studies that explored the PHN's role in screening and assessing mental health, with particular emphasis on depression, indicate that while PHNs are involved in screening and use tools to aid clinical decision making, there is a lack of consistency in approach, even when clear guidelines and protocols are available (Chew-Graham et al. 2008; Jomeen et al. 2013; Rollans et al. 2013; Borglin et al. 2015). In terms of supports provided to women, PHNs report that they provide additional open listening visits (Brown and Bacigalupo, 2006; Almond and Lathlean, 2011; Cummings and Whittaker, 2016), supportive counselling (Glavin et al. 2010b), arrange home help (Tammentie et al. 2013; Borglin et al. 2015), and refer women to a variety of health care professionals (general practitioners, counsellors, psychiatrists, psychologists and social workers) and services (mother and baby unit, community mental health teams and postnatal depression groups) (Almond and Lathlean, 2011; Rush, 2012; Rollans et al. 2013; Borglin et al. 2015). While the findings provide important insights into the role and function of the PHN, a significant issue with the studies is their emphasis on postnatal depression, with the majority exploring PHNs' practice or evaluating specific interventions focused on postnatal depression to the exclusion of other mental health problems.

\section{THE STUDY}

\section{Aim and objectives}

The aim of the study was to explore public health nurses' engagement and competence in the broader aspects of perinatal mental health care. The objectives of the study were to identify PHNs' knowledge of perinatal mental health issues, their perceived skill in providing 
perinatal mental health care to women, their current practices in perinatal mental health care, and, to establish their education needs going forward.

\section{Design}

The research design for the study was descriptive. Data for the study were collected using an anonymous, self-completed online-survey. This method was selected as it is a relatively easy and cost-effective means of obtaining structured information from participants, while its anonymity minimises the potential for socially desirable responses (Parahoo, 2006; de Vaus, 2014).

\section{Data collection}

Data for the study were collected over a 2 month period in 2016.

\section{Survey}

Data were collected using an online survey hosted on SurveyMonkey. The survey was developed by the research team based on available research in the area and consultation with practitioners and clinical experts in perinatal mental health. It used a combination of binary (yes/no), categorical, Likert scale, and open-ended questions. The topics addressed therein included: Demographic data; Contact with and caseload of women with Perinatal Mental Health Problems (PMHPs); Knowledge of perinatal mental health (19 items); Skill in perinatal mental health care (35 items); Overall skill and confidence in perinatal mental health care (2 items); Perinatal mental health practices (23 items); Previous perinatal mental health education; Perinatal mental health services and guidelines (6 items); and Educational and practice priorities ( 2 open-ended questions). 
Knowledge of perinatal mental health was rated on a scale from 1 (not at all knowledgeable) to 5 (very knowledgeable). Skill in undertaking perinatal mental health practices was also rated on a five-point scale (1 'not at all skilled' to 5 'very skilled') while overall confidence and skill in relation to perinatal mental health care practice was rated on scales from 1 to 10 .

\section{Sample and recruitment}

All PHNs registered with the Nursing and Midwifery Board of Ireland (NMBI) and employed either full-time or part-time in public health nursing services were targeted for inclusion in the study. Both agency nurses and student nurses were excluded. As there was no national database of PHNs, the sample for the survey was obtained through the Directors of Public Health Nursing within Ireland, who granted access and acted as recruitment gatekeepers by sending an email to relevant individuals within the services for distribution to the PHNs. The email contained study information, an invitation to participate and a link to the online survey. Two follow-up emails were sent by gatekeepers two weeks apart to remind potential participants to complete the surveys.

\section{Ethical considerations}

The voluntary nature and anonymity of participation in the survey was outlined in all study information, with return of the survey taken as evidence of implied consent. Ethical approval for the study was granted by the University's Research Ethics Committee and the ethics committee that approves studies involving PHNs in Ireland.

\section{Data analysis}

The survey data were analysed using the Statistical Package for the Social Sciences (SPSS), version 21 (IBM Corp 2012). Descriptive statistics, including frequency distributions, means 
and standard deviations were generated to describe the data. Independent sample t-tests were performed to examine whether they were any statistically significant differences in participants' mean skill, confidence, and knowledge scores based on prior perinatal mental health education. The educational and practice priorities identified by participants were analysed using content analysis by two researchers $(\mathrm{CD}, \mathrm{AH})$.

\section{Validity and reliability/Rigour}

The face validity of the survey was established by asking experts and specialists in the field of perinatal mental health care to review the survey and provide feedback in relation to its relevance and appropriateness as well as to identify any gaps in the survey. Practitioners from midwifery, mental health nursing and psychiatry with expertise in perinatal mental health care reviewed the survey. In addition, feedback on the survey was provided by midwives, public health nurses and practice nurses.

\section{RESULTS}

\section{Sample}

186 public health nurses completed the surveys. It was not possible to calculate a response rate given that, in the absence of a national database, it is not known how many potential participants received the survey link. However, based on national figures of the number of PHNs in Ireland $(n=1,396)$ (Office of the Nursing and Midwifery Services Director, 2012), it is estimated that $13.6 \%$ of PHNs nationally responded. The majority of PHNs were Registered General Nurses, educated to postgraduate diploma/masters level, over 45 years of age and working in their current role for over 11 years (Table 1).

\section{Knowledge of perinatal mental health}


PHNs reported relatively good knowledge on some PMH topics, such as, depression $(\mathrm{M}=3.56, \mathrm{SD}=0.83)$, anxiety $(\mathrm{M}=3.19, \mathrm{SD}=0.97)$, the impact of $\mathrm{PMH}$ problems on mother and baby $(\mathrm{M}=3.33, \mathrm{SD}=0.98)$, risk factors $(\mathrm{M}=3.15, \mathrm{SD}=0.94)$, support services available $(\mathrm{M}=3.10, \mathrm{SD}=1.01)$ and screening tools $(\mathrm{M}=3.01, \mathrm{SD}=1.17)$, with scores all above the midpoint of the scale. However, lower knowledge was rated in relation to knowledge of personality disorders $(\mathrm{M}=1.83, \mathrm{SD}=0.83)$, obsessive compulsive or ritualistic behaviour $(\mathrm{M}=1.88, \mathrm{SD}=.90)$, eating disorders and pregnancy $(\mathrm{M}=1.98, \mathrm{SD}=0.97)$, self-injury/suicide in the perinatal period $(\mathrm{M}=2.01, \mathrm{SD}=0.98)$, bipolar affective disorder $(\mathrm{M}=2.02, \mathrm{SD}=0.95)$, drug use in pregnancy and breastfeeding $(\mathrm{M}=2.07, \mathrm{SD}=0.96)$, and legal aspects $(\mathrm{M}=2.08$, $\mathrm{SD}=0.97$ ), all of which rated below the midpoint of the scale (Table 2).

\section{Overall skill and confidence}

PHNs were asked to rate their overall skill on a scale from 1 (not at all skilled) to 10 (very skilled). Overall skill in relation to perinatal mental health care was rated at a mean of 5.24 $(\mathrm{SD}=1.93$ ), just below the midpoint of the scale. On a similar scale from 1 (not at all confident) to 10 (very confident), the PHNs also rated their overall confidence below the midpoint of the scale $(\mathrm{M}=5.24, \mathrm{SD}=1.96)$.

\section{Skills in perinatal mental health activities}

Skill in undertaking a variety of perinatal mental health practices was rated on a five-point scale (1 'not at all skilled' to 5 'very skilled'). PHNs reported being most skilled in liaising with other practitioners and services (Colleagues: $\mathrm{M}=4.20, \mathrm{SD}=.92$; Managers: $\mathrm{M}=4.11$, $\mathrm{SD}=.97$; Adult mental health services: $\mathrm{M}=3.62, \mathrm{SD}=1.15$, Perinatal mental health services $\mathrm{M}=3.55, \mathrm{SD}=1.22$ ) and discussing with women referral to various services and practitioners (GP/PHN: $\mathrm{M}=4.21, \mathrm{SD}=.88$; Child Protection Services: $\mathrm{M}=3.82, \mathrm{SD}=.99$; Social worker 
$\mathrm{M}=3.64, \mathrm{SD}=1.01$; Drug and alcohol Services: $\mathrm{M}=3.56, \mathrm{SD}=1.04$; Perinatal Mental Health services: $\mathrm{M}=3.49, \mathrm{SD}=1.11$; Mental Health services: $\mathrm{M}=3.08, \mathrm{SD}=1.05)$. They also reported greater skill in asking women about $\operatorname{mood}(\mathrm{M}=3.26, \mathrm{SD}=1.00)$ and anxiety $(\mathrm{M}=3.19$, $\mathrm{SD}=1.01$ ) compared to opening a discussion with women about self-injury or suicidal thoughts/behaviours $(\mathrm{M}=2.43, \mathrm{SD}=1.02)$, alcohol and substance use $(\mathrm{M}=2.43, \mathrm{SD}=.87)$, eating disorders $(\mathrm{M}=2.22, \mathrm{SD}=.89)$, psychosis $(\mathrm{M}=2.04, \mathrm{SD}=.99)$, intimate partner violence $(\mathrm{M}=1.97, \mathrm{SD}=.91)$, and sexual abuse/violence $(\mathrm{M}=1.89, \mathrm{SD}=.87)$.

PHNs rated their skill in developing care plans for women with depression $(M=2.96$, $\mathrm{SD}=1.04)$ and anxiety $(\mathrm{M}=2.61, \mathrm{SD}=1.12)$ highest, and lowest in developing care plans with women who had thoughts of harming themselves $(\mathrm{M}=2.44, \mathrm{SD}=1.18)$ or the baby $(\mathrm{M}=2.44$, $\mathrm{SD}=1.17)$, or were experiencing obsessive thoughts $(\mathrm{M}=2.11, \mathrm{SD}=1.02)$, delusions $(\mathrm{M}=2.03$, $\mathrm{SD}=1.04)$ or hearing voices $(\mathrm{M}=2.03, \mathrm{SD}=1.03)$. PHNs also reported greater skill in providing support to women who were traumatised by their birth experience $(M=3.61$, $\mathrm{SD}=1.01)$ and emotionally distressed $(\mathrm{M}=3.37, \mathrm{SD}=.99)$ compared to providing support to those concerned about taking psychotropic medication $(\mathrm{M}=2.66, \mathrm{SD}=1.03)$ or concerned about the hereditary nature of mental health problems $(\mathrm{M}=2.55 ; \mathrm{SD}=.99)$ (Table 3).

\section{Caseload}

Information about caseloads was obtained by asking PHNs to estimate how many women experiencing a mental health issue they had cared for in the previous six months. Over 70\% of PHNs reported caring for women with perinatal mental health problems, with the majority reporting caring for between 1-5 women in the previous 6 months (Table 4).

\section{Perinatal mental health care practice}


Over $80 \%$ of PHNs reported including mental health as a dimension of their assessment with women $(87 \%, \mathrm{n}=127)$ and asking women about their past mental health history/diagnosis $(83.6 \%, \mathrm{n}=122)$ in their clinical practice (Table 5). While over $80 \%$ reported asking women about mood disorder (all women: 56.2\%, $\mathrm{n}=82$; women identified at risk: 30.1\%, $\mathrm{n}=44$ ), psychological support available to them (all women: $54.1 \%, \mathrm{n}=79$; women identified at risk: $34.2 \%, \mathrm{n}=50$ ), and coping strategies (all women: $34.2 \%, \mathrm{n}=50$; women identified at risk: $48.6 \%, \mathrm{n}=71$ ), between $70-80 \%$ of PHNs reported never asking any woman about sexual abuse/sexual violence $(81.5 \%, \mathrm{n}=119)$, intimate partner violence $(77 \%, \mathrm{n}=112)$ or experience of eating disorders $(70.5 \%, \mathrm{n}=103)$. Half of PHNs reported never asking any woman about past and current alcohol use $(52.1 \%, \mathrm{n}=76)$ or substance misuse $(52.1 \%, \mathrm{n}=76)$, with between $30-40 \%$ never asking any woman about psychosis $(40.4 \%, n=59)$, self-injury/suicide thoughts $(35 \%, \mathrm{n}=52)$, past trauma/grief $(34 \%, \mathrm{n}=50)$ or anxiety/panic/OCD $(31 \%, \mathrm{n}=46)($ Table 5$)$.

Although $73 \%$ reported identifying women at risk of perinatal mental health problems, and approximately $70 \%$ indicated that they used screening tools $(69.9 \%, n=102)$ to identify women at risk, just 55\% reported developing a care plan with women who had a pre-existing mental health diagnosis. In the context of other supports to women and their family, just $60 \%$ $(60.3 \%, n=88)$ reported discussing women's concerns related to psychopharmacology in pregnancy and breastfeeding, and providing information on PMHPs to women's partners/family $(59.6 \%, \mathrm{n}=87)$ (Table 5).

\section{Education on perinatal mental health}

Approximately $40 \%$ of PHNs reported that they never received education on perinatal mental health with approximately $41 \%$ reporting the availability of perinatal mental health education within their service $(41.3 \%, \mathrm{n}=69)$. Of those who received education, $40 \%$ had attended in- 
service education, with the largest number indicating their perinatal mental health education was from their nurse/midwifery training. Those that had some PMH education had statistically significant higher confidence than those without PMH education (M=5.69; $\mathrm{SD}=1.78$ vs. $\mathrm{M}=4.50, \mathrm{SD}=1.95)(\mathrm{t}(93.128)=3.40, \mathrm{p}<.001)$ and also statistically significant higher skill $(\mathrm{M}=5.69, \mathrm{SD}=1.78$ vs. $\mathrm{M}=4.50, \mathrm{SD}=2.04)$ than those without any $\mathrm{PMH}$ education $(\mathrm{t}(129)=3.588, \mathrm{p}<.001)$. They also had statistically significant higher self-rated knowledge on all knowledge items compared to those without PMH education (Table 6).

\section{Perinatal mental health services and guidelines}

Nearly $60 \%$ of PHNs either reported an absence of policies or guidelines, or did not know if policies or guidelines on perinatal mental health existed, within their service $(57.5 \%, \mathrm{n}=96)$. Approximately one third of PHNs reported that there wasn't a designated place in women's health record to document a mental health history/assessment $(28.1 \%, \mathrm{n}=47)$, while $44 \%$ $(n=74)$ indicated the absence of a designated place in women's record to document a mental health plan of care for women. Just over $50 \%$ of PHNs reported having guidelines on care pathways within their services $(55.7 \%, \mathrm{n}=93)$ and having access to specialist perinatal mental health services $(52.1 \%, \mathrm{n}=87)$ (Table 7).

\section{Educational and practice priorities}

Educational priorities identified by PHNs fell into three categories. The first category of need was knowledge of perinatal mental health issues, including the types, risk factors, medication issues, cultural differences, and attachment and bonding. The second category was education to enhance interviewing, assessment, support and counselling skills. The third category concerned the nature, format and context of perinatal mental health education, with specific 
requests for regular, up-to-date, education from mental health specialist with opportunities for practical application of skills.

Practice priorities identified by PHNs included: increasing specialist perinatal services and supports for women and their partners/families; developing organisational care pathways, protocols, and guidelines to improve consistency and continuity of care; improved integration and communication between services and disciplines; and support to increase the amount of time available to PHNs to discuss mental health problems with women in the perinatal period. Perinatal mental health education and promotion for the general public, women and all clinical staff was also identified as a priority.

\section{DISCUSSION}

This is the first study in Ireland that explores PHNs knowledge, skill and practice in relation to perinatal mental health care, and the first internationally that has comprehensively examined PHNs' practices on the range of mental health issues that may impact on women in the perinatal period. Most PHNs involved in the study encountered women with PMHPs; however, the caseload of women cared for in the previous six months was reported as mostly between 1-5 women. While this number may suggest that PHNs do not meet women with mental health problems very frequently, it more likely represents an under-detection of women experiencing PMHPs given that NICE (2014) estimate that 15-25\% of women will experience a mental health problem either during pregnancy or in the first year postpartum.

Findings also clearly indicate that PHNs possess better knowledge on some aspects of perinatal mental health, namely, depression, anxiety, risk factors, screening tools, and the impact of PMHPs on the mother and baby, compared to other areas, such as, bipolar affective 
disorder, obsessive compulsive or ritualistic behaviour, eating disorders, self-injury/suicide in the perinatal period, personality disorders, drug use in pregnancy and breastfeeding, and legal aspects. Skills were also rated comparatively low in many of the areas where there were perceived deficits in knowledge. PHNs reported low skill levels in opening a discussion and asking women about psychosis, intimate partner violence, sexual abuse/violence and eating behaviours, as well as minimal skills in developing care plans with women who had thoughts of harming themselves or their baby, or were experiencing obsessive thoughts, delusions or hearing voices. Given that much of the international research involving PHNs tends to focus on postnatal depression, it is difficult to make comparisons; however, similar to the findings of this study, available research suggests that PHNs lack confidence in their skill and ability to gather information, identify and respond to the wide range of perinatal mental health issues (Agapidaki et al. 2014; Rollans et al. 2013 ), and are unsure about how to distinguish between distress which could be resolved with support and mental health problems that require specialist intervention (McConnell et al. 2005; Agapidaki et al. 2014).

In terms of screening and assessing women within practice, the study findings highlight that while PHNs generally enquire about women's mental health history, their experience of a range of perinatal mental health problems is not routinely investigated. High numbers of PHNs do not ask women about their trauma history, in particular intimate partner violence, sexual abuse/sexual violence, their history of eating disorders and psychosis or thoughts of self-injury/suicide. In other studies, mood, feelings and depression have been found to be key factors considered in the assessment of women's mental health, while salient risk factors, such as, history of self-harm/suicide, sexual abuse and domestic violence were rarely assessed routinely (Baldwin \& Griffiths, 2009; Rollans et al. 2013). Personal discomfort and a perception that asking about these issues is too 'confronting' for women were identified as 
factors contributing to PHNs and maternal child health nurses silence around these issues (Lau et al, 2015; Rollans et al, 2013).

The apparent reluctance of some PHNs to enquire about, or discuss the range of mental health problems such as psychosis and risk factors such as domestic violence also leaves women vulnerable and without adequate information and support. Evidence indicates that women with a prior history of psychosis (schizophrenia/ previous postpartum psychosis) (MunkOlsen et al. 2009) or women with a diagnosis of bipolar disorder, especially those who discontinue psychotropic treatment or stop medication abruptly (Viguera et al. 2007; Wesseloo et al. 2016) are at an increased risk of relapse and developing postpartum psychosis. In addition, evidence also incidences a rise in the rates of domestic violence in pregnancy (Jeanjot et al. 2008; Taillieu and Brownridge, 2010), therefore PHNs need to adopt a more comprehensive approach towards screening and assessment of risk factors for mental health problems.

This study also indicates that there is a practice of 'selective screening', as most PHNs indicated that they only asked women with identified risk factors about their mental health rather than all women. The practice of 'selective screening' has been found in other studies, particularly in relation to domestic violence screening, with health professionals favouring 'selective' screening over routine screening in the belief that 'suspected cases' can be easily identified (Jeanjot et al. 2008). The potential implication of relying on selective screening is that women without an obvious presentation will be missed. Similarly, relying only on personal judgment may also result in those with significant risk factors, including those with a history of mental health problems not receiving the support required in the perinatal period (Heneghan et al. 2007; Anding et al. 2015). There is no doubt that the practice of exclusion 
or selective screening is a reflection of PHNs' self-reported lack of knowledge and skill in perinatal mental health compounded by a lack of education and organisational practice guidelines (Higgins et al. 2017). It may also be a reflection of the wider public discourse, as internationally mental health literacy tends to be focused on depression and postnatal depression. Indeed, women in Higgins et al. 's (2016) Irish study were of the view that a 'conspiracy of silence' existed around wider perinatal mental health issues, such as psychosis and this was not just among the general public but among health practitioners.

While enquiring about and screening for past mental health problems or trauma experiences is important, the process of screening and assessment is only of value if it is followed with a plan of care, developed in collaboration with women (Borglin et al. 2015; Higgins et al. 2017) and other practitioners, such as members of the mental health team, or if a referral to specialist mental health services is made where appropriate. It was found in this study that care planning was not routinely practised by PHNs, as only 55\% of the participants identified it as a core dimension of their practice and $65 \%$ of PHNs reported referring women to mental health services. While the lack of knowledge and skill found in relation to care planning in this study may account for some of the deficits in practice, especially in relation to care planning with women who experience obsessive thinking, have thoughts of harming themselves or their baby, hear voices or have delusional thinking, the lack of engagement with women about their mental health plan of care may also be attributed to poor support and guidance within services, as the study found that just over half of services had a place to document a mental health plan (53\%). The absence of care pathways and services may also influence PHNs' practice, as several studies have shown that PHNs encounter difficulties in care planning following identification of a perinatal mental health problem, namely, due to the absence of clear referral pathways (Jomeen et al. 2013), a lack of knowledge about 
community resources or a perception of inadequate services (Agapidaki et al. 2014), and a lack of resources and time to provide support and care to women with perinatal mental health issues (Chew-Graham et al. 2008; Rush, 2012; Borglin et al. 2015). These deficits, which are also reported in this study, resulted in some PHNs in other studies viewing identification of mental health problems as pointless (Chew-Graham et al. 2008) or being afraid to discuss mental health problems with women (Jomeen et al. 2013).

An important component of primary prevention of PMHPs is providing information to women a range of perinatal mental health problems which may develop, in order to increase awareness of signs and symptoms, to reduce stigma and fear around disclosure, and to alert them to help that is available (Glavin et al. 2010a; Tammentie et al. 2013). The provision of information is also important as it enables women to challenge 'myths' and 'fantasies' about pregnancy and motherhood (Tammentie et al. 2013; Borglin et al. 2015) and address mental health problems should they arise. While findings from this study suggest that the majority of PHNs discussed some aspects of mental health with women between $30-40 \%$ did not do so. In addition, self-reported skill level in providing information to women around psychotropic medication use and breastfeeding, and information about the hereditary nature of mental health problems was relatively low. While the lack of skill in relation psychopharmacology may be due to the lack of knowledge found among PHNs in this study, it may also be related to a perception that information provision on psychopharmacology is outside PHNs' role, as PHNs in other studies regard identification and diagnosis of depression and the provision of information related to prescribed medication to be the domain of practice of General Practitioners (McConnell et al. 2005; Chew-Graham et al. 2008). Whilst the provision of specialist information on the use of psychopharmacology during pregnancy and breastfeeding is certainly the remit of the prescribing medical practitioner, PHNs need to be knowledgeable 
on the side-effects and know where, and how, to refer women for evidence-based information.

The provision of information to the woman's partner, significant other or family members is also regarded as essential in aiding their supportive other(s) to recognise when they require help and this practice is viewed as integral to facilitating a good outcome for the woman and indeed the whole family (Higgins, 2012; Stein et al. 2014; Higgins et al. 2017). The study results show that the provision of information on PMH to women's partners and family was practised by just $60 \%$ of PHNs, while skill in providing support to the woman's partner and family on various aspects of mental health were rated below the midpoint of the scale. PHNs in this study recognised the need for education on communicating and providing support to women's partners/family.

Education is recognised as essential to enhancing practitioners' confidence in perinatal mental health care (Glavin et al. 2010a; Jomeen et al. 2013), as is the availability of practitioner support, mentoring and supervision (Vik et al. 2009; Rush, 2012). The importance of education is evidenced in this study, as findings suggest that PHNs with PMH education had statistically significant higher self-reported confidence, skill and knowledge scores than those without any PMH education. However, for education to be truly impactful, it must be comprehensive, address the range of mental health issues (Jomeen et al. 2013), incorporate cultural competency (Almond \& Lathlean, 2011), and be up-to-date and contemporary. $39 \%$ of PHNs in this study reported not having received any education in perinatal mental health, with those who reported receiving education, reporting that, for the most part, it was during their nursing/midwifery training, which, given the age profile and length of time participants reported working in their current role, suggests that education 
received is potentially outdated. Deficits in education provision and inadequate preparation for their role in supporting women's perinatal mental health has been identified by PHNs in numerous studies (Almond \& Lathean, 2011; Rollans et al. 2013; Agapidaki et al. 2014; Beauchamp, 2014), and some PHN's engage in self-directed learning, such as internet searching and accessing journal information, to fill gaps in knowledge (Brown and Bacigalupo, 2006). Like other studies, PHNs in this study identified education as an important priority (McConnell et al. 2005; Brown and Bacigalupo, 2006; Skočir and Hundley 2006; Mivsek et al. 2008; Almond and Lathlean, 2011; Agapidaki et al. 2014), with education being sought in relation to the range of PMHPs, incidence and risk factors as well as broader topics such as bonding and attachment, and cultural and legal issues. Indeed, the low self-reported knowledge on legal aspects of caring for women experiencing mental health problems is concerning given that women may require emergency or involuntary mental health treatment and the PHN may play an active role in this process. Additionally, as with the PHNs in Agapidakei et al.'s (2014) study, the PHNs in this study also prioritised education and training in communication skills and strategies to enhance their comfort and confidence to have a discussion on all aspects of mental health with women, and not just depression.

\section{LIMITATIONS}

The generalisability of the study findings is limited by the fact that it is unknown whether the sample obtained was representative of the PHN population and the fact that response bias may have been present with those more positively disposed to perinatal mental health care completing the survey. Another limitation of the study is that PHNs' practices are selfreported, so there is no way of knowing how consistent the reported practice is with their actual clinical practice. A final limitation of this study is that there may have been a 
heightened risk of making a Type 1 error, that is detecting a statistically significant difference when in fact none is present, due to the fact that multiple analyses were conducted.

\section{CONCLUSION}

This paper demonstrates that PHNs have greater competence in some areas of perinatal mental health, such as postnatal depression, and report less knowledge, skill and confidence to identify, support and care for women who experience a broad range of other mental health problems in the perinatal period. This is no doubt related to perinatal mental health education and a lack of organisational guidelines to support their practice. The findings from this study clearly indicate that PHNs are positive about their role in supporting women who experience mental health issues; however, they desire the education and guidance to support them to identify women's needs, communicate on sensitive subjects and provide the necessary evidence-based support to women and their families.

\section{RELEVANCE TO CLINICAL PRACTICE}

This study has significant implications for education, practice and research. If PHNs are to provide comprehensive care, they need to be confident to discuss and plan for a range of perinatal mental health problems with women, such as psychosis, bipolar disorders, depression during pregnancy, eating disorders, suicide, obsessive or ritualistic behaviour, the use of psychotropic medication and legal issues of care. They also need to have knowledge in how to access the expertise and support of mental health practitioners in caring for women with mental health issues. In addition, there is a need for services to review their documentation to ensure that mental health is visible as an aspect of assessment and care planning, and that guidelines and care pathways are available to support PHNs in their role. 


\section{REFERENCES}

Agapidaki, E., Souliotis, K., Jackson, S. F., Benetou, V., Christogiorgos, S., Dimitrakaki, C., \& Tountas, Y. (2014). Pediatricians' and health visitors' views towards detection and management of maternal depression in the context of a weak primary health care system: a qualitative study. BMC Psychiatry, 14, 108-108. doi: 10.1186/1471-244X$14-108$

Almond, P., \& Lathlean, J. (2011). Inequity in provision of and access to health visiting postnatal depression services. Journal of Advanced Nursing, 67(11), 2350-2362. doi: 10.1111/j.1365-2648.2011.05669.x

Anding, J., Röhrle, B., Grieshop, M., Schücking, B., \& Christiansen, H. (2015). Early Detection of Postpartum Depressive Symptoms in Mothers and Fathers and Its Relation to Midwives' Evaluation and Service Provision: A Community-Based Study. Frontiers in Pediatrics, 3, 62. doi: 10.3389/fped.2015.00062

Baldwin, S., \& Griffiths, P. (2009). Do specialist community public health nurses assess risk factors for depression, suicide, and self-harm among South Asian mothers living in London? Public Health Nursing, 26(3), 277-289. doi: 10.1111/j.15251446.2009.00780.x

Barber, C. C. (2009). Perinatal Mental Health Care in New Zealand: The Promise of Beginnings. New Zealand Journal of Psychology, 38(1), 32-38.

Beauchamp, H. (2014). What factors influence the use of the Whooley questions by health visitors? Journal of Health Visiting, 2(7), 378-387. doi: 10.12968/johv.2014.2.7.378

Beyondblue. (2008). Annual Report 08/09: beyondblue: the national depression initiative. Australia: Beyondblue.

Borglin, G., Hentzel, J., \& Bohman, D. M. (2015). Public health care nurses' views of mothers' mental health in paediatric healthcare services: a qualitative study. Prim 
Health Care Research and Development, 16(5), 470-480. doi:

$10.1017 / \mathrm{s} 1463423615000055$

Brown, H., \& Bacigalupo, R. (2006). Health visitors and postnatal depression: identification and practice. Community Practitioner, 79(2), 49-52.

Challacombe, F. L., \& Wroe, A. L. (2013). A hidden problem: consequences of the misdiagnosis of perinatal obsessive-compulsive disorder. The British Journal of General Practice, 63(610), 275-276. doi: 10.3399/bjgp13X667376

Chew-Graham, C., Chamberlain, E., Turner, K. M., Folkes, L., Caulfield, L., \& Sharp, D. (2008). GPs' and health visitors' views on the diagnosis and management of postnatal depression: a qualitative study. The British Journal of General Practice, 58(548), 169176. doi: 10.3399/bjgp08X277212

Cummings, E., \& Whittaker, K. (2016). Listening visits by health visitors as an intervention for mild-to-moderate postnatal depression or anxiety. Journal of Health Visiting, 4(5), 264-270. doi: 10.12968/johv.2016.4.5.264

de Vaus, D. (2014). Surveys in Social Research (6th ed.). London: Routledge.

Desai, R. J., Hernandez-Diaz, S., Bateman, B. T., \& Huybrechts, K. F. (2014). Increase in prescription opioid use during pregnancy among Medicaid-enrolled women. Obstet Gynecol, 123(5), 997-1002. doi: 10.1097/aog.0000000000000208

Glasser, S., Hadad, L., Bina, R., Boyko, V., \& Magnezi, R. (2016). Rate, risk factors and assessment of a counselling intervention for antenatal depression by public health nurses in an Israeli ultra-orthodox community. Journal of Advanced Nursing, 72(7), 1602-1615. doi: 10.1111/jan.12938

Glavin, K., Ellefsen, B., \& Erdal, B. (2010a). Norwegian public health nurses' experience using a screening protocol for postpartum depression. Public Health Nursing, 27(3), 255-262. doi: 10.1111/j.1525-1446.2010.00851.x 
Glavin, K., Smith, L., Sorum, R., \& Ellefsen, B. (2010b). Supportive counselling by public health nurses for women with postpartum depression. Journal of Advanced Nursing, 66(6), 1317-1327. doi: 10.1111/j.1365-2648.2010.05263.x

Health Service Executive (HSE). (2016). Perinatal Statistics Report 2014. Dublin: HSE. IBM Corp. (2012). IBM SPSS Statistics for Windows, Version 21.0. Armonk, NY: IBM Corp.

Heneghan, A. M., Morton, S., \& DeLeone, N. L. (2007). Paediatricians' attitudes about discussing maternal depression during a paediatric primary care visit. Child: Care Health and Development, 33(3), 333-339. doi: 10.1111/j.1365-2214.2006.00648.x

Higgins, A. (2012). Postpartum psychosis. In C. R. Martin (Ed.), Perinatal Mental Health: A Clinical Guide. UK: M\&K Publishing.

Higgins, A., Carroll, M., Downes, C., Monahan, M., Gill, A., Madden, D., . . Nagel, U. (2017). Perinatal mental health: an exploration of practices, policies, processes and education needs of nurses and midwives within maternity and primary care services in Ireland. Dublin: Health Service Executive.

Higgins, A., Tuohy, T., Murphy, R., \& Begley, C. (2016). Mothers with mental health problems: Contrasting experiences of support within maternity services in the Republic of Ireland. Midwifery, 36, 28-34. doi: 10.1016/j.midw.2016.02.023

Hinton, L., Locock, L., \& Knight, M. (2015). Support for mothers and their families after life-threatening illness in pregnancy and childbirth: a qualitative study in primary care. The British Journal of General Practice, 65(638), e563-e569. doi: 10.3399/bjgp15X686461

Jeanjot, I., Barlow, P., \& Rozenberg, S. (2008). Domestic violence during pregnancy: survey of patients and healthcare providers. Journal of Womens Health (Larchmt), 17(4), 557-567. doi: 10.1089/jwh.2007.0639 
Jomeen, J., Glover, L., Jones, C., Garg, D., \& Marshall, C. (2013). Assessing women's perinatal psychological health: exploring the experiences of health visitors. Journal of Reproductive and Infant Psychology, 31(5), 479-489. doi:

$10.1080 / 02646838.2013 .835038$

Lau, R., McCauley, K., Barnfield, J., Moss, C., \& Cross, W. (2015). Attitudes of midwives and maternal child health nurses towards suicide: A cross-sectional study. International Journal of Mental Health Nursing, 24(6), 561-568. doi: 10.1111/inm.12162

McConnell, J., Baker, M., \& Marks, L. (2005). Experiencing a dilemma--accounts of working with PND. Community Practitioner, 78(7), 251-254.

Mivsek, A. P., Hundley, V., \& Kiger, A. (2008). Slovenian midwives' and nurses' views on post-natal depression: an exploratory study. International Nursing Review, 55(3), 320326. doi: 10.1111/j.1466-7657.2008.00620.x

Munk-Olsen, T., Laursen, T. M., Mendelson, T., Pedersen, C. B., Mors, O., \& Mortensen, P. B. (2009). Risks and predictors of readmission for a mental disorder during the postpartum period. Archives of General Psychiatry, 66(2), 189-195. doi: 10.1001/archgenpsychiatry.2008.528

NICE. (2007). Antenatal and postnatal mental health: Clinical management and service guidance. Clinical guideline [CG45]. London: NICE.

NICE. (2014). Antenatal and postnatal mental health: clinical management and service guidance: Clinical guideline [CG192]. London: NICE.

Noonan, M., Galvin, R., Doody, O., \& Jomeen, J. (2017). A qualitative meta-synthesis: public health nurses role in the identification and management of perinatal mental health problems. Journal of Advanced Nursing, 73(3), 545-557. doi: 10.1111/jan. 13155 
Office of the Nursing and Midwifery Services Director. (2012) Report on Current Public Health Nursing Services; Report prepared by Patricia O’ Dwyer, Project Officer to the Expert Advisory Group on Public Health Nursing Services

Parahoo, K. (2006). Nursing Research: Principles, Process and Issues (2nd ed.). Houndsmill: Palgrave Macmillan.

Passey, M. E., Sanson-Fisher, R. W., D'Este, C. A., \& Stirling, J. M. (2014). Tobacco, alcohol and cannabis use during pregnancy: clustering of risks. Drug and Alcohol Dependence, 134, 44-50. doi: 10.1016/j.drugalcdep.2013.09.008

Rollans, M., Schmied, V., Kemp, L., \& Meade, T. (2013). Negotiating policy in practice: child and family health nurses' approach to the process of postnatal psychosocial assessment. BMC Health Services Research, 13(1), 133. doi: 10.1186/1472-6963-13133

Rush, P. (2012). The experience of maternal and child health nurses responding to women with postpartum depression. Maternal Child Health Journal, 16(2), 322-327. doi: $10.1007 / \mathrm{s} 10995-010-0688-2$

Scottish Intercollegiate Guidelines Network (SIGN). (2012). Management of perinatal mood disorders: A national clinical guideline. www.sign.ac.uk/guidelines/fulltext/127/ [Accessed 04/05/2017].

Skočir, A. P., \& Hundley, V. (2006). Are Slovenian midwives and nurses ready to take on a greater role in caring for women with postnatal depression? Midwifery, 22(1), 40-55. doi: 10.1016/j.midw.2005.05.001

Stein, A., Pearson, R. M., Goodman, S. H., Rapa, E., Rahman, A., McCallum, M., Howard, L. M., \& Pariante, C. M. (2014). Effects of perinatal mental disorders on the fetus and child. The Lancet, 384(9956), 1800-1819. doi: 10.1016/S0140-6736(14)61277-0

Taillieu, T. L., \& Brownridge, D. A. (2010). Violence against pregnant women: Prevalence, 
patterns, risk factors, theories, and directions for future research. Aggression and Violent Behavior, 15(1), 14-35. doi: 10.1016/j.avb.2009.07.013

Tammentie, T., Paavilainen, E., Åstedt-Kurki, P., \& Tarkka, M. T. (2013). Public health nurses in Finland help to prevent postnatal depression. Primary Health Care, 23(1), 26-31. doi: 10.7748/phc2013.02.23.1.26.e724

Vesga-Lopez, O., Blanco, C., Keyes, K., Olfson, M., Grant, B. F., \& Hasin, D. S. (2008). Psychiatric disorders in pregnant and postpartum women in the United States. Archives of General Psychiatry, 65(7), 805-815. doi: 10.1001/archpsyc.65.7.805

Viguera, A. C., Whitfield, T., Baldessarini, R. J., Newport, D. J., Stowe, Z., Reminick, A., Zurick, A., \& Cohen, L. S. (2007). Risk of recurrence in women with bipolar disorder during pregnancy: prospective study of mood stabilizer discontinuation. The American Journal of Psychiatry, 164(12), 1817-1824; quiz 1923. doi: 10.1176/appi.ajp.2007.06101639

Vik, K., Aass, I. M., Willumsen, A. B., \& Hafting, M. (2009). "It's about focusing on the mother's mental health": screening for postnatal depression seen from the health visitors' perspective--a qualitative study. Scandinavian Journal of Public Health, 37(3), 239-245. doi: 10.1177/1403494808100275

Watson, H. J., Von Holle, A., Hamer, R. M., Berg, C. K., Torgersen, L., Magnus, P., . . Bulik, C. M. (2013). Remission, continuation, and incidence of eating disorders during early pregnancy: A validation study on a population-based birth cohort. Psychological medicine, 43(8), 1723-1734. doi: 10.1017/S0033291712002516

Wesseloo, R., Kamperman, A. M., Munk-Olsen, T., Pop, V. J., Kushner, S. A., \& Bergink, V. (2016). Risk of Postpartum Relapse in Bipolar Disorder and Postpartum Psychosis: A Systematic Review and Meta-Analysis. American Journal of Psychiatry, 173(2), 117127. doi: 10.1176/appi.ajp.2015.15010124 
World Health Organisation (WHO). (2013). WHO recommendations on postnatal care of the mother and newborn. Geneva: WHO.

Wisner, K. L., Sit, D. K., McShea, M. C., Rizzo, D. M., Zoretich, R. A., Hughes, C. L., . . Hanusa, B. H. (2013). Onset timing, thoughts of self-harm, and diagnoses in postpartum women with screen-positive depression findings. JAMA Psychiatry, 70(5), 490-498. doi: 10.1001/jamapsychiatry.2013.87

\section{Acknowledgments}

We would like to acknowledge the Office of the Nursing \& Midwifery Services, HSE Ireland for funding, the Directors of Public Health Nursing for their assistance and the Public Health Nurses for taking the time to complete the survey. 
Table 1: Demographic profile

\begin{tabular}{|c|c|c|c|}
\hline & & $\mathbf{N}$ & $\%$ \\
\hline \multirow[t]{4}{*}{ Age } & $25-34$ years & 20 & 10.8 \\
\hline & $35-44$ years & 47 & 25.2 \\
\hline & $45-54$ years & 78 & 41.9 \\
\hline & $55+$ & 41 & 22.0 \\
\hline \multirow[t]{3}{*}{ Highest level of qualification } & Certificate/Diploma & 30 & 16.2 \\
\hline & Degree & 22 & 11.8 \\
\hline & $\begin{array}{l}\text { Postgraduate } \\
\text { diploma/Masters }\end{array}$ & 134 & 72 \\
\hline \multirow[t]{4}{*}{ Midwifery/Nursing Qualification* } & RGN & 175 & - \\
\hline & RM & 148 & - \\
\hline & RPN & 41 & - \\
\hline & RSCN/RNID/RNP/RMP & 20 & - \\
\hline \multirow[t]{3}{*}{ Area employed } & $\begin{array}{l}\text { Public health nursing } \\
\text { services }\end{array}$ & 173 & 93.0 \\
\hline & Community services & 6 & 3.2 \\
\hline & Other & 7 & 3.8 \\
\hline \multirow[t]{3}{*}{ Length of time in role } & $0-5$ & 38 & 20.4 \\
\hline & $6-10$ & 47 & 25.3 \\
\hline & 11 years+ & 101 & 54.3 \\
\hline
\end{tabular}

*Participants could select more than one answer 
Table 2: Self-rated knowledge of perinatal mental health $(n=138)$

\begin{tabular}{|l|c|c|}
\hline How would you rate your knowledge (1-5) on: & Mean & SD \\
\hline Perinatal depression (antenatal and postnatal depression) & 3.56 & .83 \\
\hline Impact of maternal mental health problems on mothering & 3.33 & .98 \\
\hline Perinatal anxiety (antenatal and postnatal anxiety) & 3.19 & .97 \\
\hline Risk factors for developing mental health problems in the perinatal period & 3.15 & .94 \\
\hline Services available to support women with perinatal mental health issues & 3.10 & 1.01 \\
\hline Screening tools for perinatal mental health problems & 3.01 & 1.17 \\
\hline Impact of maternal mental health problems on the foetus/baby & 3.01 & 1.03 \\
\hline Obsessive thinking related to perinatal mental health & 2.38 & 1.02 \\
\hline Alcohol misuse in the perinatal period & 2.38 & 1.00 \\
\hline Psychosis in the perinatal period & 2.35 & 1.04 \\
\hline Post-traumatic stress disorder & 2.22 & .98 \\
\hline Substance misuse in the perinatal period & 2.21 & 1.00 \\
\hline Legal aspects of caring for women experiencing mental health problems, and their babies & 2.08 & .97 \\
\hline Drug use in pregnancy and breastfeeding & 2.07 & .96 \\
\hline Bipolar affective disorder & 2.02 & .95 \\
\hline Self-injury/suicide in perinatal period & 2.01 & .98 \\
\hline Eating disorders and pregnancy & 1.98 & .97 \\
\hline Obsessive compulsive or ritualistic behaviour & 1.88 & .90 \\
\hline Personality disorders & 1.83 & .83 \\
\hline
\end{tabular}


Table 3: Self-rated skills in undertaking perinatal mental health activities

\begin{tabular}{|c|c|c|c|}
\hline \multicolumn{2}{|c|}{ Rate your skill in: } & \multirow{2}{*}{$\begin{array}{c}\text { Mean } \\
3.26\end{array}$} & \multirow{2}{*}{$\begin{array}{c}\text { SD } \\
1.00\end{array}$} \\
\hline \multirow{8}{*}{$\begin{array}{c}\text { Opening a } \\
\text { discussion and } \\
\text { asking women } \\
\text { about: }\end{array}$} & Mood & & \\
\hline & Anxiety & 3.19 & 1.01 \\
\hline & Self-injury or suicidal thoughts/behaviours & 2.43 & 1.02 \\
\hline & Alcohol and substance use & 2.43 & .87 \\
\hline & Eating behaviours & 2.22 & .89 \\
\hline & Psychosis & 2.04 & .99 \\
\hline & Intimate partner violence & 1.97 & .91 \\
\hline & Sexual abuse / sexual violence & 1.89 & .87 \\
\hline \multirow{5}{*}{$\begin{array}{c}\text { Providing } \\
\text { support } \\
\text { (informational, } \\
\text { emotional, } \\
\text { practical) to } \\
\text { women who } \\
\text { are: }\end{array}$} & Traumatised by their birth experience & 3.61 & 1.01 \\
\hline & Emotionally distressed & 3.37 & .99 \\
\hline & Concerned that they may develop mental health problems & 3.24 & .96 \\
\hline & $\begin{array}{l}\text { Concerned about taking psychotropic medication while pregnant or } \\
\text { breastfeeding }\end{array}$ & 2.66 & 1.03 \\
\hline & Concerned about the hereditary nature of mental health problems & 2.55 & .99 \\
\hline \multirow{5}{*}{$\begin{array}{c}\text { Providing } \\
\text { support to } \\
\text { partners/ } \\
\text { family } \\
\text { members who } \\
\text { are concerned } \\
\text { about: }\end{array}$} & The safety of the baby & 3.19 & .98 \\
\hline & The woman's mental health & 3.08 & .96 \\
\hline & Own mental health & 3.08 & .95 \\
\hline & The woman's safety & 3.04 & .95 \\
\hline & The impact of the woman's mental health on foetus/baby & 2.98 & .98 \\
\hline \multirow{7}{*}{$\begin{array}{c}\text { Developing a } \\
\text { plan of care } \\
\text { with women } \\
\text { who: }\end{array}$} & Are experiencing depression & 2.96 & 1.04 \\
\hline & Are experiencing severe anxiety & 2.61 & 1.12 \\
\hline & Have thoughts about harming their baby & 2.44 & 1.18 \\
\hline & Have thoughts about harming themselves & 2.44 & 1.17 \\
\hline & Have obsessive thinking & 2.11 & 1.02 \\
\hline & Are hearing voices & 2.03 & 1.03 \\
\hline & Are having strange or unusual thoughts (delusions) & 2.03 & 1.04 \\
\hline \multirow{6}{*}{$\begin{array}{c}\text { Discussing } \\
\text { with women } \\
\text { the need to } \\
\text { consult with } \\
\text { and/or refer } \\
\text { to: }\end{array}$} & Primary care (GP/Public Health Nurse) & 4.21 & .88 \\
\hline & Child Protection Services & 3.82 & .99 \\
\hline & Social worker & 3.64 & 1.01 \\
\hline & Drug and alcohol Services & 3.56 & 1.04 \\
\hline & Perinatal Mental Health services (nurse/midwife/psychiatrist) & 3.49 & 1.11 \\
\hline & Mental Health services (nurse /psychiatrist/psychologist/counsellor) & 3.08 & 1.05 \\
\hline \multirow{4}{*}{$\begin{array}{c}\text { Asking for } \\
\text { advice or } \\
\text { assistance on } \\
\text { mental health } \\
\text { issues from: }\end{array}$} & Colleagues & 4.20 & .92 \\
\hline & Managers & 4.11 & .97 \\
\hline & Adult mental health services & 3.62 & 1.15 \\
\hline & \begin{tabular}{|l} 
Perinatal mental health services \\
\end{tabular} & 3.55 & 1.22 \\
\hline
\end{tabular}


Table 4: No. of women experiencing perinatal mental health issues cared for in the past 6 months

\begin{tabular}{|l|l|l|}
\hline No. of women & $\mathbf{N = 1 2 5}$ & \% \\
\hline $1-5$ & 99 & 79.2 \\
\hline $6-10$ & 15 & 12.0 \\
\hline $11-15$ & 9 & 7.2 \\
\hline $16+$ & 2 & 1.6 \\
\hline
\end{tabular}


Table 5: Perinatal mental health activities and assessment practices

\begin{tabular}{|c|c|c|c|}
\hline In your clinical practice, do you? & Yes & No & $\begin{array}{l}\text { Not } \\
\text { part } \\
\text { of } \mathbf{m y} \\
\text { role }\end{array}$ \\
\hline $\begin{array}{l}\text { Include mental health as a dimension of the assessment you complete } \\
\text { with women }\end{array}$ & 87 & 4.8 & 8.2 \\
\hline Ask women about their past mental health history/ diagnosis & 83.6 & 8.9 & 7.5 \\
\hline $\begin{array}{l}\text { Identify women's protective/coping strategies for maintaining mental } \\
\text { health }\end{array}$ & 78.1 & 13.7 & 8.2 \\
\hline Discuss the nature of perinatal mental health problems with women & 74 & 14.4 & 11.6 \\
\hline Identify women at risk of perinatal mental health problems & 73.3 & 13.7 & 13 \\
\hline Use mental health tools to screen for or assess mental health problems & 69.9 & 21.9 & 8.2 \\
\hline Refer women to mental health services & 64.4 & 22.6 & 13 \\
\hline $\begin{array}{l}\text { Discuss women's concerns related to psychopharmacology in } \\
\text { pregnancy and breastfeeding }\end{array}$ & 60.3 & 27.4 & 12.3 \\
\hline $\begin{array}{l}\text { Provide information on perinatal mental health problems to women's } \\
\text { partners/family }\end{array}$ & 59.6 & 28.8 & 11.6 \\
\hline $\begin{array}{l}\text { Develop a care plan with women who have a pre-existing mental health } \\
\text { diagnosis }\end{array}$ & 54.8 & 34.9 & 10.3 \\
\hline $\begin{array}{l}\text { Refer women with mental health issues to child protection services } \\
\text { (indirectly through social worker or directly) }\end{array}$ & 50.7 & 42.5 & 6.8 \\
\hline Do you ask women about? & $\begin{array}{l}\text { Never } \\
\text { ask a } \\
\text { woman }\end{array}$ & $\begin{array}{l}\text { Ask } \\
\text { women } \\
\text { with } \\
\text { mental } \\
\text { health } \\
\text { risk } \\
\text { factors }\end{array}$ & $\begin{array}{l}\text { Ask all } \\
\text { women }\end{array}$ \\
\hline Experience of sexual abuse/sexual violence & 81.5 & 16.4 & 2.1 \\
\hline Experience of eating disorders & 70.5 & 24.7 & 4.8 \\
\hline Experience of intimate partner violence & 76.7 & 17.8 & 5.5 \\
\hline Experience of psychosis & 40.4 & 52.7 & 6.8 \\
\hline Self-injury/suicidal thoughts/behaviour & 35.6 & 50.7 & 13.7 \\
\hline Past and current substance use & 52.1 & 32.2 & 15.8 \\
\hline Past and current alcohol use & 52.1 & 27.4 & 20.5 \\
\hline Experience of anxiety/panic/OCD & 31.5 & 41.8 & 26.7 \\
\hline Past trauma/grief/loss experiences & 34.2 & 38.4 & 27.4 \\
\hline Usual mental health coping strategies & 17.1 & 48.6 & 34.2 \\
\hline Psychological support available to them & 11.6 & 34.2 & 54.1 \\
\hline Experience of mood disorders (depression, bipolar affective disorder) & 13.7 & 30.1 & 56.2 \\
\hline
\end{tabular}


Table 6: Knowledge among those with and without some perinatal mental health education

\begin{tabular}{|c|c|c|c|c|c|c|c|}
\hline \multirow[b]{3}{*}{ Knowledge } & \multicolumn{6}{|c|}{ Some Education in PMH } & \multirow[b]{3}{*}{ T-Test } \\
\hline & \multicolumn{3}{|l|}{ Yes } & \multicolumn{3}{|c|}{ No } & \\
\hline & $\mathbf{N}$ & Mean & SD & $\mathbf{N}$ & Mean & SD & \\
\hline $\begin{array}{l}\text { Risk factors for developing } \\
\text { mental health problems in } \\
\text { the perinatal period }\end{array}$ & 86 & 3.43 & .83 & 52 & 2.69 & .92 & $\begin{array}{l}\mathrm{t}(136)=4.847 \\
\mathrm{p}<.001^{* * *}\end{array}$ \\
\hline $\begin{array}{l}\text { Perinatal depression } \\
\text { (antenatal and postnatal } \\
\text { depression) }\end{array}$ & 86 & 3.71 & .76 & 52 & 3.31 & .88 & $\begin{array}{l}\mathrm{t}(136)=2.829 \\
\mathrm{p}=.005^{* *}\end{array}$ \\
\hline $\begin{array}{l}\text { Perinatal anxiety (antenatal } \\
\text { and postnatal anxiety) }\end{array}$ & 86 & 3.37 & .91 & 52 & 2.88 & 1.00 & $\begin{array}{l}\mathrm{t}(136)=2.937 \\
\mathrm{p}=.004^{* *}\end{array}$ \\
\hline $\begin{array}{l}\text { Obsessive thinking related } \\
\text { to perinatal mental health }\end{array}$ & 86 & 2.60 & 1.00 & 52 & 2.02 & .96 & $\begin{array}{l}\mathrm{t}(136)=3.389, \\
\mathrm{p}<.001^{* * *}\end{array}$ \\
\hline $\begin{array}{l}\text { Screening tools for perinatal } \\
\text { mental health problems }\end{array}$ & 86 & 3.29 & 1.05 & 52 & 2.56 & 1.21 & $\begin{array}{l}\mathrm{t}(136)=3.748, \\
\mathrm{p}<.001^{* * *}\end{array}$ \\
\hline $\begin{array}{l}\text { Eating disorders and } \\
\text { pregnancy }\end{array}$ & 86 & 2.12 & .99 & 52 & 1.75 & .90 & $\begin{array}{l}\mathrm{t}(136)=2.178 \\
\mathrm{p}=.031^{*}\end{array}$ \\
\hline $\begin{array}{l}\text { Psychosis in the perinatal } \\
\text { period }\end{array}$ & 86 & 2.53 & 1.01 & 52 & 2.04 & 1.01 & $\begin{array}{l}\mathrm{t}(136)=2.792, \\
\mathrm{p}=.006^{* *}\end{array}$ \\
\hline Bipolar affective disorder & 86 & 2.16 & .98 & 52 & 1.79 & .87 & $\begin{array}{l}\mathrm{t}(136)=2.265 \\
\mathrm{p}=.025^{*}\end{array}$ \\
\hline $\begin{array}{l}\text { Post-traumatic stress } \\
\text { disorder }\end{array}$ & 86 & 2.36 & 1.05 & 52 & 1.98 & .80 & $\begin{array}{l}\mathrm{t}(128.482)=2.388, \\
\mathrm{p}=.018^{*}\end{array}$ \\
\hline $\begin{array}{l}\text { Psychotropic drug use in } \\
\text { pregnancy and breastfeeding }\end{array}$ & 86 & 2.23 & .94 & 52 & 1.81 & .93 & $\begin{array}{l}\mathrm{t}(136)=2.581 \\
\mathrm{p}=.011^{*}\end{array}$ \\
\hline $\begin{array}{l}\text { Self-injury/suicide in } \\
\text { perinatal period }\end{array}$ & 86 & 2.20 & 1.02 & 52 & 1.69 & .83 & $\begin{array}{l}\mathrm{t}(136)=3.029 \\
\mathrm{p}=.003^{* *}\end{array}$ \\
\hline $\begin{array}{l}\text { Alcohol misuse in the } \\
\text { perinatal period }\end{array}$ & 86 & 2.53 & .99 & 52 & 2.12 & .96 & $\begin{array}{l}\mathrm{t}(136)=2.436 \\
\mathrm{p}=.016^{*}\end{array}$ \\
\hline $\begin{array}{l}\text { Substance misuse in the } \\
\text { perinatal period }\end{array}$ & 86 & 2.36 & 1.00 & 52 & 1.96 & .95 & $\begin{array}{l}\mathrm{t}(136)=2.307 \\
\mathrm{p}=.023^{*}\end{array}$ \\
\hline Personality Disorders & 86 & 2.00 & .87 & 52 & 1.56 & .70 & $\begin{array}{l}\mathrm{t}(136)=3.116 \\
\mathrm{p}=.002^{* *}\end{array}$ \\
\hline
\end{tabular}




\begin{tabular}{|c|c|c|c|c|c|c|c|}
\hline $\begin{array}{l}\text { Obsessive compulsive or } \\
\text { ritualistic behaviour }\end{array}$ & 86 & 2.14 & .88 & 52 & 1.46 & .75 & $\begin{array}{l}\mathrm{t}(136)=4.612, \\
\mathrm{p}<.001^{* * *}\end{array}$ \\
\hline $\begin{array}{l}\text { Impact of maternal mental } \\
\text { health problems on the } \\
\text { foetus/baby }\end{array}$ & 86 & 3.21 & .92 & 52 & 2.69 & 1.11 & $\begin{array}{l}\mathrm{t}(136)=2.951, \\
\mathrm{p}=.004^{* *}\end{array}$ \\
\hline $\begin{array}{l}\text { Impact of maternal mental } \\
\text { health problems on } \\
\text { mothering }\end{array}$ & 86 & 3.50 & .88 & 52 & 3.06 & 1.09 & $\begin{array}{l}\mathrm{t}(136)=2.613, \\
\mathrm{p}=.010^{*}\end{array}$ \\
\hline $\begin{array}{l}\text { Services available to } \\
\text { support women with } \\
\text { perinatal mental health } \\
\text { issues }\end{array}$ & 86 & 3.31 & .95 & 52 & 2.75 & 1.01 & $\begin{array}{l}\mathrm{t}(136)=3.306, \\
\mathrm{p}<.001^{* * *}\end{array}$ \\
\hline $\begin{array}{l}\text { Legal aspects of caring for } \\
\text { women experiencing mental } \\
\text { health problems, and their } \\
\text { babies }\end{array}$ & 86 & 2.26 & .96 & 52 & 1.79 & .94 & $\begin{array}{l}\mathrm{t}(136)=2.797, \\
\mathrm{p}=.006^{* *}\end{array}$ \\
\hline
\end{tabular}


Table 7: Perinatal mental services and guidelines

\begin{tabular}{|l|c|c|c|}
\hline Does your service have? & Yes & No & $\begin{array}{c}\text { Don't } \\
\text { know }\end{array}$ \\
\hline $\begin{array}{l}\text { A designated place in women's record to document a mental health } \\
\text { history/assessment }\end{array}$ & 68.9 & 28.1 & 3 \\
\hline Care pathways for women experiencing a mental health problem & 55.7 & 32.3 & 12 \\
\hline $\begin{array}{l}\text { A designated place in women's record to document a mental health plan of } \\
\text { care for women }\end{array}$ & 52.7 & 44.3 & 3 \\
\hline Access to specialist perinatal mental health services & 52.1 & 36.5 & 11.4 \\
\hline Policy/guidelines on perinatal mental health & 42.5 & 37.1 & 20.4 \\
\hline In-service education on perinatal mental issues & 41.3 & 45.5 & 13.2 \\
\hline
\end{tabular}

